\title{
Child Abuse and Neglect: Psychological Impact and Role of Social Work
}

\author{
Adi Fahrudin \\ Department of Social Welfare, University of Muhammadiyah Jakarta \\ J1 KH Ahmad Dahlan, Southern Jakarta, Indonesia \\ Tel: 62-21-749-2875 E-mail: fahradi@gmail.com \\ Faculty of Psychology and Education, Universiti Malaysia Sabah \\ 88999 Kota Kinabalu, Sabah, Malaysia \\ Tel: 60-88-320-000 E-mail: adi.fahrudin@ums.edu.my

\section{Husmiati Yusuf} \\ Center for Social Welfare Research and Development \\ Ministry of Social Affairs, Republic of Indonesia \\ Jl. Dewi Sartika 200 Cawang III, Jakarta Timur
}

Tel: 62-21-8017146 E-mail: umi_yusuf2015@gmail.com

Mohd Dahlan H. A. Malek

Faculty of Psychology and Social Work, Universiti Malaysia Sabah 88999 Kota Kinabalu, Sabah, Malaysia

Tel: 60-88-320-000 E-mail: dahlanam@ums.edu.my

Received: January 14, 2016 Accepted: March 16, 2016 Published: March 19, 2016

doi:10.5296/ijsw.v3i1.8842ＵRL: http://dx.doi.org/10.5296/ijsw.v3i1.8842

\begin{abstract}
Child welfare is considered a special area of practice within the profession of social work, and the principles and values of the social work profession generally fit with policies that guide modern child welfare organizations. In most countries, social workers in child welfare
\end{abstract}


agencies have a minimum of a requirement and are registered with a government body that holds them accountable for competent and ethical practice. Child abuse can affect personality growth and later adult behavior. A social worker is closely connected with the study of causes, with treatment and associated research. Underpinning that mission is the belief that all societies have a duty to aim for an abuse-free environment. It needs to be recognized by students that working in this area can be very stressful for the professionals concerned. Interventions require exposure to deviant and stressful situations, which can, over time, affect the mental health of workers themselves. In some situations, dealing with criminal perpetrators can also be threatening and dangerous.

Keywords: Child abuse and neglect, Child welfare agencies, Social work, Psychological impact, Policy

\section{Introduction}

This paper is a general introduction to the subject of child abuse for social work students making an initial study of that topic. Child abuse is a major and universal social problem that affects children from all sectors of society. As a field of study, it is complex and far-ranging, drawing on different disciplines and theories, across the life span. For example, in some countries, dealing with historical abuse and later grievances has become a major industry involving helping professionals, advocates, lawyers and even the insurance industry.

As abuse in childhood can affect personality growth and later adult behavior, social workers are closely connected with the study of causes, with treatment and associated research. Underpinning that mission is the belief that all societies have a duty to aim for an abuse-free environment. It needs to be recognized by students that working in this area can be very stressful for the professionals concerned. Interventions require exposure to deviant and stressful situations, which can over time affect the mental health of workers themselves. In some situations, dealing with criminal perpetrators can also be threatening and dangerous.

The paper is structured in three major parts. Part 1 is concerned with the definitional, historical and contextual elements of child abuse. Part II concentrates on the psychological impact of abuse on the individual person. The response of human service agencies and professionals forms Part III. Internet resources and selected readings for the Malaysian context are given at the end.

\section{Definitional, Contextual, and Historical Elements of Child Abuse}

Child abuse defies easy definitions. The issues are dealt with first in this section, followed by culture and context considerations, and a brief historical comment. The eight major categories of child abuse, as found in the child welfare laws of most developed countries are then detailed.

\subsection{Definitional Issues}

As a rough indicator of the extent of activity in this field, an internet search showed 880,000 citations for the keywords 'child abuse'. Child abuse is universal and most countries have laws about child abuse, but there are no universal definitions because the concept of child abuse and neglect is socially constructed. Therefore, consideration must always be made of the social context in which the alleged abuse occurs. One way of defining child abuse is by stating the conditions under which the child develops in an abuse-free lifestyle. When those 
conditions or rights are absent, the child is at risk of abuse. The best universal guidelines are found in the United Nations 'Convention on the Rights of the Child'.

\subsection{Cultural Issues}

In both the physical punishment and sexual status of children, there are wide cultural differences to be found. Some cultures have a higher tolerance of parental, caregiver or teacher violence towards children than others do. Some countries have 'zero tolerance' against hitting children, even by parents, and such violence is socially constructed as a crime. In other cultures, hitting children is an acceptable parental or caregiver right. Similarly, cultures vary on their threshold ages for sexual maturity, and activities that are defined as crimes in one country may be commonplace in another. Generally, the more 'developed' the country, the longer the age at which children and young people are accorded adult status.

Problems can occur for families migrating from more-to-less tolerant cultures, or where cultural practices are in opposition. For example, migrant families from certain African states, which practice female circumcision, face the dilemma that such practices constitute child abuse in their adopted countries. In addition, within countries, there may be 'sub-cultural' differences. For example, the conditions under which the poor and dispossessed struggle to live often give rise to crime and violence, including abuse against children, as defined by the dominant cultural groups.

\subsection{Brief Historical Background}

Traditionally, in the West, children were viewed as the property of their parents. Thus, parents (usually meaning fathers) held life-and-death power over their offspring. While social provisions have always been made for children who were abandoned or orphaned, it is only in the last 150 years that society ('the State') has intervened to protect children by overriding the rights of parents. Up to that time, the so-called 'Industrial Revolution', and before the invention of compulsory education by attendance at school, most children led lives little different from adults.

Although in our generation, we may regard the special rights of children and everyday ways of protecting them, as 'common sense' and natural, it was not always the case. As we see in the next section, the potential conflict between the rights of parents and the rights of children remains one of the contestable issues in the field of child welfare. It is worth noting, as a telling item of historical trivia, that most Western countries had laws protecting the welfare of animals before they had laws protecting children.

\subsection{Eight Descriptors of Child Abuse and Neglect}

The following eight sections set out the main categories of child abuse and neglect where protective services may be involved (for a fuller account, see Kadushin \& Martin, 1988).

\subsubsection{Physical Abuse}

This ranges from hitting children to the extreme of torture. There may be only a fine line between 'discipline' by parents or teachers and 'violence' to children. Clearly, it amounts to abuse when the child suffers some physical harm, whether intended or not. Most physical abuse of children occurs in their own home, followed by the school setting. The practice of 'bullying' by other children can lead to physical abuse. Medicine and psychology have developed the concept of Non-accidental Injury (NAI), and there are well-developed 


\section{MInstitute ${ }^{\text {Macrothink }}$}

protocols for making such judgments. In some countries, doctors, nurses, teachers and other professionals who suspect that a child's injuries may have been deliberately caused are required by law to report the incident to child protection agencies. Criminal charges may result against the parent or caregiver. More than any other child-rearing practice that of hitting children as a means of control has resulted in changed social attitudes over the last century. The saying that 'a child who lives with violence, learns to be violent' arose out of the belief that aggression in parents produces either similar aggression or other behavioral disorders in their children. Some countries ban hitting by parents and/or teachers (so-called 'corporal punishment'), together with all the other ways in which physical harm might be done to children, such as extreme physical exercise as a form of punishment.

\subsubsection{Neglect}

In general, this category covers instances where food, clothing, housing, or parental care and attention is inadequate. These incidents are so-called 'acts of omission', that is, by doing nothing to care for the child it potentially or actually suffer some risk of harm. The common legal test of whether a parent or caregiver has been guilty of neglect is by asking the question 'what would any reasonable parent have done in those circumstances'. Neglect is often associated with inadequate parenting. Sociologists have coined the phrase 'the cycle of deprivation' to explain why certain inadequate child-rearing practices seem to occur in subsequent generations. The basic theory is that we tend to behave in the same way as our families of origin. Improved education and life chances can help to break the cycle. Social workers and other helping professionals are struggle with the concept of 'dirty but happy' families. That is, although the parents seem to be inadequate in material terms, the children seem loved and happy. The dilemma for child protection agencies is whether to make interventions that may fragment the family.

\subsubsection{Inadequate Medical Care}

This sub-category of neglect is the failure to provide minimum medical care for illness or accident through ignorance, poverty or religious beliefs. Again, the test is what other parents from the same socio-economic grouping could be expected to do in health care for their children. Failure to provide disease immunization where this is offered free can also be considered in this category. One of the most difficult areas for child protection agencies is the denial of medical care for children on the grounds of religious or spiritual beliefs. This frequently arises in the West with certain Christian sects whose faith precludes blood transfusions or similar intrusive medical treatment.

\subsubsection{Non-attendance at School}

Compulsory education systems are now a growing universal trend. The consequences of not attending school (or being legally educated at home) so affect a person's life chances that it is considered bad for children not to attend. Also associated with the category of neglect, non-attendance may be for reasons of parental personal beliefs, but more often it arises from inadequate parenting. There may be elements of exploitation where parents or guardians keep the child from school to carry out work. In some special cases, social workers also need to consider 'school aversion' and 'school phobia' when untreated. These instances arise when sick or difficult children develop strong resistance to going to school. Some may successfully 
manipulate their parents into letting them stay away from school. Such cases often give rise to florid personality disorders in later life.

\subsubsection{Exploitation}

Developed countries have laws regulating the entry age, the type, places, hours and conditions of work that children may undertake. It becomes exploitation when children are required to undertake work which is not appropriate according to the laws of the country. However, children can be exploited in ways other than just their labour. For example, the practice of disfiguring children to work as beggars is an attempt to exploit the sympathy of the public. Similarly, many would say that children are often exploited in the images portrayed in some visual advertising. Universally, unfair child labour is a massive problem, some of which borders on slavery. It can be both an urban and a rural problem.

\subsubsection{Amoral Environment}

In this category, children may be treated well, but exposed to criminal, sexual or deviant behaviours which can affect their personality development. Children growing up in a criminal sub-culture or in a prostitution household are considered particularly at risk. Making a judgment about children at risk in these circumstances is often a difficult task for child protection agencies. Solely because the family does not live or behave like other families is not sufficient reason for an intervention, as it has to be legally demonstrated that the child will suffer harm if not removed.

\subsubsection{Sexual Abuse}

Sexual abuse is any inappropriate contact between adults and children, or with other children. Most sexual abuse takes place in the child's home, or by an adult known to the child. Universally, there are prescriptions against sexual activity, or 'incest', between close relatives of any age. The dynamics of this type of abuse, especially intra-familial episodes, often make it difficult for the victim to disclose the abuse to a responsible adult. Therefore, much child abuse goes undetected in childhood, and only comes to light when the victim feels able to make disclosures, often when undergoing treatment for dysfunctional behavior, symptomatic of the abuse trauma. The issue in addressing incidents of past abuse has become a major activity in the West, where instances of systematic abuse of children has been revealed, often in residential settings such as children's homes or orphanages. The more clear cut extra-familial cases are those involving juvenile prostitution or the deviant practices of 'ritual abuse' of children by groups of adults for satanic worship.

\subsection{8 'Emotional' Abuse}

Deprivation of affection or denial of growth relationships can also be damaging to personality development. In this category, the child is deliberately denied feelings of being loved, wanted, secure and worthy. The child may be the target of 'shaming and blaming' behaviors by parents, leading to feelings of worthlessness and low self-esteem. Symptoms of emotional abuse usually indicate family psychopathology, but in the absence of physical evidence it is usually difficult for child protection agencies both to diagnosis and to prove. On the whole, most child welfare theories of recent times have promoted the idea of 'minimal intervention', that is, taking severe action, such as the removal of the child from the home, only as a measure of last resort. This arises out of findings that the intervention may actually prove to 


\section{Macrothink}

reduce the chances of healthy adjustment for the child.

\subsection{Where and Who?}

Abuse situations also have to be classified according to where the abuse takes place and who is the abuser. There are the two main distinctions of 'intra-familial abuse and neglect' and 'extra-familial abuse'. In the latter case, distinctions are also necessary between assaults by strangers and by those known to the child. As stated earlier, children are most at risk in their homes or in foster homes, and from abuse by those known to them. 'In loco parentis' abuse occurs when the abuser is acting as the parent or caregiver to the child. Many countries have special laws which give harsher penalties to those abusers who betray their guardianship of the child placed in their care on trust.

\section{The Psychological Impact of Abuse}

\subsection{Unique Impacts}

Abuse will have a different impact on different people. That is, the same type of abuse done to different children will have different consequences for them both at the time and later in life. Some of the complex factors involved are: the personality of the child; its 'resilience', or ability to overcome and deal with adverse life events; the nature and timing of the disclosure (if ever); the family setting and support; later life chances. Therefore, there is no such thing as a 'scale of seriousness' as far as victims are concerned. The law does classify types of crimes, of course, but within each classification the actual event will vary in the degree of aggression, duration, and frequency. It is commonplace for perpetrators (abusers) or their lawyers to argue in defense of the crime that on a scale of offending the particular act was less serious than others are. For example, it may be argued that inappropriate touching of a child is less serious than penetration. However, the predisposition of the child will determine what the abuse means to it, and the factors listed earlier will determine recovery from the abuse.

\subsection{Common Impacts}

The following elements are common risks to victims of abuse.

- Most victims of abuse will suffer from feelings of shame and loss of self-esteem (Victims often feel "I must be a worthless person if this is being done to me").

- Many will also be continuing victims, for periods running over years or even decades.

- Many will feel threatened about disclosing abuse, especially in intra-familial situations. Child victims are often threatened with family fragmentation if they disclose, and children may feel guilty about that prospect. Abusing fathers often say "if you tell, I'll go to prison and you'll be put in a children's home, and it will be your fault".

- Many will suffer long-term effects (see PTSD below).

- Some become abusers themselves. Again, this is often used as an excuse for offending by the perpetrator or his lawyer. While it may help explain the offender's actions, most professionals accept that from young adulthood men must accept responsibility for their own actions.

\subsection{Post-Traumatic Stress Disorder}

Post-traumatic stress disorder (PTSD) is a classifiable psychiatric condition as set out in the Diagnostic and Statistical Manual (DSM) of the American Psychiatric Association. It is the 
general term given to people who have psychological squeal from unusual events, such as disasters, violence, emotional upheavals, and forms of abuse. The principal symptoms are free-floating anxiety, impaired functioning, inability with relationships, and low self-esteem (amongst others). To meet the test for this disorder, the patient's symptoms must be directly traceable to a distinct, known event or series of events.

\section{Role of Social Workers Related Child Abuse}

Ideally, of course, we would all wish to see a kind of society free from child abuse of any type. As societies have become more complex and we have moved from village life to impersonal and large-scale urban communities, so too have we invented complex organizations for social control. This section lists the common primary (or 'frontline') agencies concerned with child abuse, special units of those agencies, and secondary agencies. The issue of multi-problem cases is noted, followed by treatment provisions for victims, and treatment approaches for offenders. The section concludes with an outline of the role of social workers in child abuse and its treatment.

\subsection{Primary Agencies}

- The Police (where criminal offences are disclosed)

- Child Welfare or Child Protection agencies, either governmental or mandated by the State.

- The Law Courts, criminal, Children and Youth Courts, and Family Court jurisdictions

- Telephone 'hotlines' (e.g. Child Help Line, Rape Crisis and similar agencies)

\subsection{Special Units}

- Both the Police and child protection (CP) agencies may have dedicated sections for the investigation and prosecution of abuse allegations (e.g., rape suites).

- Inter-agency teams. As physical and sexual abuse can involve experts and professionals from different agencies, special arrangements are often made for these people to work as a team on the same cases. These may be called 'multi-problem cases'. Commonly, serious cases of abuse involve more than one category amongst listed in Part I above. Thus, where there is more than symptom, there may be more than one agency involved (for example, the Police, social services, health services). Such teams help in the co-ordination of intervention. From this practice has grown the concepts of 'Lead agency' and 'key therapist', meaning those who will be in charge of a case.

- CP agencies may include 'evidential interviewing' (EI) for younger children. EI is the practice where an adult talks to a young victim or witness and gives evidence on his or her behalf to a Court. This requires both specially trained professionals and special 'child-friendly' accommodation.

- Victim support units, and NGOs providing services to victims and their families, are often called in when abuse is disclosed.

\subsection{Secondary Agencies}

Any organization which deals with children and their families has a responsibility to be alert to the signs of abuse, or non-accidental injury, in their charges. Even in the absence of signs and symptoms, these places may also be the site of disclosures of abuse by troubled children. 


\section{Macrothink}

For those reasons, the staff of such places should have special training in detection, interviewing and reporting of abuse.

- Schools, including pre-school centers

- General medical clinics, allied health services

- Hospitals and health centers

- Domiciliary services (home visiting)

- Adult offender treatment centers

4.4 Mandatory Reporting

Mandatory reporting (MR) is the practice where the government by law requires any professional person suspecting child abuse to report it to a central co-ordinating agency. This normally covers doctors, nurses, teachers of children at all ages, specialist therapists and so on. There are arguments for and against. Those for MR believe that it is the right of all children to be protected by every adult. Those against, believe that MR can interfere with the professional relationship (say between doctor and patient) which may help the patient to resolve the problem.

\subsection{Treatment Services}

In Western countries, the following treatment modalities may arise as a consequence of abuse being disclosed. These will be age-specific, in that some are adult treatments, others for children.

- Counseling (individual or group)

- Psychotherapy

- Support groups

- Extra-familial care for children

- Foster care or adoption

- Residential care

- Day care

\subsection{Treatment for Offenders}

Many countries also have well-developed treatment programs for the perpetrators of abuse (the 'offenders'), especially for adult men with violence and/or sexual offending histories. Some victims groups believe that prison is the only remedy for such men and that the taxpayer money spent on men should be spent on victims instead. Against that view, supporters of programs for men point that many men go undetected until they have a large number of victims. Giving preventative therapy as early as possible will help to reduce that number;

- Prison-based treatments, such as anger management or sexual offending cessation programs.

- Mandated treatment, or treatment ordered by a Court as a part of the sentence, in the categories that follow.

- Anger management courses. These use cognitive-behavioral techniques in group therapy settings to help show men the consequences of their behavior and to seek change in it. 


\section{Macrothink

- Parenting courses may be made available to inadequate parents, or those with alcohol or drug problems, who are motivated to try to keep the family intact.

- Sexual offending rehabilitation. Similar to anger management in structure, community-based programs stress that their real clients are the men's victims. A willingness to acknowledge both one's offending and motivation to change are the conditions for being accepted into such programs.

- Psychotherapy may be offered to a few offenders, in prison or on parole, who show good prospects of benefiting from it. As child-sex offenders frequently get badly treated by other inmates in prison, they are at risk of self-destructive behaviors (suicide) and often need professional help to cope.

- Private (fee-paying) treatments are also available to those past offenders who can afford them.

\subsection{The Role of Social Workers}

Social workers are one of the professional groups working with victims and their families, and with perpetrators and their families, and together with social workers, are the experts most likely to be offering therapeutic programs. The following areas are those where social workers are active in the area of child abuse such as;

- Clinical examinations of victims using diagnostic measures.

- Forensic investigations into the causation, offending patterns and the likelihood of repeat offending by serious perpetrators. This will usually be done on the remand wing of a prison or secure psychiatric hospital.

- Advising and reporting to parents, schools, protection agencies and Courts.

- Evidential interviewing and expert testimony (see above).

- Counseling (individual, family and group).

- Psychosocial therapy (including play therapy).

- Training, including volunteers, for victim support programs, mutual support groups, anger management and rehabilitation programs.

- Work with offenders, either in prison-based or community-based programs.

\section{Conclusion}

Child abused is major social problem that affects children from all sector of society. But there are not universal definitions because concept of child abused and neglect is socially constructed. Child abused is also problem of cultural issues. It's different from one culture to other culture. Many categories of child abuse and neglect such as physical, neglect, inadequate medical care, non-attendance at school, exploitation, amoral environment, sexual abuse, and emotional abuse. Child abused will be unique and common impact including PTSD among the victims. In this situation, role of social work is very important in treatment and intervention especially in primary agencies, special unit, secondary agencies, mandatory, and treatment service. Other role of social worker in this issue is doing treatment for offenders. It's because social workers are one of the professional group working with child abuse victims and their families, and with perpetrators and their families, and together with 
other professionals offering therapeutic program.

\section{References}

American Psychiatric Association. (1994). Diagnostic and statistical manual of mental disorders (4th ed.). Washington, DC: Author.

Cormier, S., \& Hackney, H. (1999). Counseling strategies and intervention (5th ed). Boston: Allyn and Bacon.

Doyle, C. (1994) Child sexual abuse: A guide for health professionals. London, Chapman \& Hall. http://dx.doi.org/10.1007/978-1-4899-3364-5

Edward, D., \& Fahrudin, A. (2004). Trauma, coping behavior and social functioning of the child sexual assault victims. Paper will present at ICSW 31st International Conference, Kuala Lumpur, 16-20 August 2004.

Fahrudin, A. (2002). Kanak-kanak jalanan di Kota Kinabalu: Kajian kes anak-anak pendatang asing asal Philippina. Laporan Penelitian. Kota Kinabalu: Universiti Malaysia Sabah.

Ferrara, F. F. (2002). Childhood sexual abuse: Developmental effects across the lifespan. Brooks/Cole: Pacific Grove, CA. http://dx.doi.org/10.1016/S0145-2134(02)00345-9

Finkelhor, D. (1984). Child sexual abuse: New theory and research. New York: Free Press.

Fredy, J. R., \& Donkervoet, J. C. (1995). Traumatic stress: An overview of the field. In J. Dalam, R. Freedy, \& S. Hobfoll (Eds.), Traumatic stress from theory to practice (pp. 3-28). New York: Plenum Press. http://dx.doi.org/10.1007/978-1-4899-1076-9_15

Glaser, D., \& Frosh, S. (1988) Child sexual abuse. London, Macmillan.

Helfer, R. E., \& Kempe, R. S. (eds). (1987). The battered child. Chicago, University of Chicago Press.

Kadushin, A., \& Martin, A. J. (1988). Child welfare services (4th ed.). New York, Macmillan.

Kasmini, K., \& Mohd Sham, K. (1995). Psychological aspects of 101 cases of child abuse seen in an urban Malaysia setting. International Journal of Child Abuse and Neglect, 19(7), 793-799. http://dx.doi.org/10.1016/0145-2134(95)00047-C

Koompraphant, S. et al. (2002). Case management guidelines for child protection and care services. Paper presented at the ILO-IPEC South Asian Technical Seminar on Psychosocial Rehabilitation and Occupational Integration of Child Survivors of Trafficking, Kathmandu, Nepal.

Mohd Sham, K. (1995). Child sexual abuse as detected by the SCAN Team, Hospital Kuala Lumpur. Proceedings of the Third National Conference on Child Abuse and Neglect. Institute of Paediatrics, Hospital Kuala Lumpur.

O'Hagen, K. P. (1995). Emotional and psychological abuse: problems of definition. Child Abuse and Neglect, 19(4), 449-461. http://dx.doi.org/10.1016/0145-2134(95)00006-T

Van der Kolk, B. A. (1996). Trauma and memory. In Dalam B. Van der Kolk, A. C. McFarlane, \& L. Weisaeth (Eds.), Traumatic stress: The effects of overwhelming experience on mind, body and society (pp. 279-302). New York: Guildford Press.

Vonk, M. E., \& Yegidis, B. L. (1998). Post-traumatic stress disorder. In B. Dalam, A. Thyer, 


\section{Macrothink}

International Journal of Social Work

ISSN 2332-7278 2016, Vol. 3, No. 1

\& J. S. Wodarski. (Eds.), Handbook of empirical social work practice. Vol 1. New York: John Wiley \& Sons. Inc.

\section{Glossary}

$\mathrm{CP}=$ Child protection

$\mathrm{MR}=$ Mandatory reporting

$\mathrm{EI}=$ Evidential interviewing

DSM $=$ Diagnostic and Statistical Manual

PTSD $=$ Post-traumatic stress disorder

\section{Copyright Disclaimer}

Copyright reserved by the author(s).

This article is an open-access article distributed under the terms and conditions of the Creative Commons Attribution license (http://creativecommons.org/licenses/by/3.0/). 